\title{
GnRH analogues may increase endometrial Hoxa10 promoter methylation and affect endometrial receptivity
}

\author{
FEI LI, MING ZHANG, YUANZHEN ZHANG, TENG LIU and XINLAN QU \\ Department of Obstetrics and Gynecology, Reproductive Medicine Center, \\ Zhongnan Hospital of Wuhan University, Wuhan, Hubei 430071, P.R. China
}

Received October 13, 2013; Accepted May 2, 2014

DOI: $10.3892 / \mathrm{mmr} .2014 .2680$

\begin{abstract}
The present study aimed to investigate whether gonadotropin-releasing hormone analogues (GnRH-as), including GnRH agonists and antagonists, affect endometrial homeobox (Hox) a10 DNA methylation during the implantation window in mice. GnRH analogue mouse models were used and were treated with either human menopausal gonadotropin (HMG) and a GnRH agonist or HMG and a GnRH antagonist. Uterus samples were collected $48 \mathrm{~h}$ after $\mathrm{GnRH}$ analogue treatment or ovulation. Bisulfite sequencing polymerase chain reaction (PCR), quantitative-PCR and western blot analysis were performed to assess Hoxa10 and integrin $\beta 3$ expression. Scanning electron microscope analyses were conducted to analyze pinopode development. Compared with the natural cycle control mice, mice in the GnRH analogue groups were found to exhibit increased levels of methylation at the Hoxa10 promoter, decreased Hoxa10 mRNA and protein expression and disrupted pinopode development. These findings suggest that GnRH-as may be associated with altered Hoxa10 DNA methylation, thus GnRH-as may affect uterine Hoxa10 expression and endometrial receptivity.
\end{abstract}

\section{Introduction}

Controlled ovarian hyperstimulation $(\mathrm{COH})$ is an effective method of assisted reproductive technology (ART) to stimulate the generation of more oocytes than are produced during natural cycles (1). Despite the increase in the number of embryos generated using $\mathrm{COH}$, pregnancy rates following ART remain low at 20-30\% per fresh cycle (2). Several studies and meta-analyses have shown that the gonadotropin-releasing

Correspondence to: Professor Yuanzhen Zhang, Department of Obstetrics and Gynecology, Reproductive Medicine Center, Zhongnan Hospital of Wuhan University, 169 Donghu Road, Wuhan, Hubei 430071, P.R. China

E-mail: 1151877287@qq.com

Key words: DNA methylation, endometrial receptivity, Hoxa10, gonadotropin-releasing hormone agonist, gonadotropin-releasing hormone analogue, gonadotropin-releasing hormone antagonist hormone analogues (GnRH-as), including GnRH agonists and antagonists, which are used in $\mathrm{COH}$, may have negative effects on endometrial receptivity (3-5). However, the mechanisms regulating endometrial receptivity deficiency following GnRH-as treatment remain to be elucidated $(2,4)$.

Homeobox (HOX) A10/Hoxa10 (human/mouse), respectively) is a homeobox-containing transcription factor that regulates embryo uterine development and is essential for endometrial development during each menstrual cycle in adults (6-7). Hoxa10 targeted mutation Hoxa10 (-/-) mice ovulate normally, but $\sim 80 \%$ are sterile due to the low expression of maternal Hoxa10 in the distal oviductal and uterine epithelium, which may affect embryo implantation (8). Hoxa10 is a characteristic molecular marker of endometrial receptivity with peak expression exhibited during the window of implantation (9). Hoxa10 has been demonstrated to be involved in the regulation of pinopode development and downstream target genes, which are involved in implantation, including integrin $\beta 3(10-12)$.

Impaired endometrial receptivity is associated with altered Hoxa10 methylation. Abnormal expression of Hoxa10 has been found to be associated with disrupted endometrial receptivity in several diseases, including endometrial carcinoma, endometriosis, endometrial polyps, ovarian cancer, polycystic ovary syndrome and in conditions associated with exposure to diethylstilbestrol and bisphenol-A (13-18). However, few studies have demonstrated the association between the uterine methylation status and alterations in endometrial receptivity following $\mathrm{GnRH}$-as therapies. The present study aimed to investigate the uterine methylation status of the Hoxa10 gene following GnRH-as treatment in order to explore the potential mechanism underlying the epigenetic effect of GnRH-as on endometrial receptivity.

\section{Materials and methods}

Animals. Animal care and use was conducted according to the institutional guidelines established by the Animal Care and Use Committee of Wuhan University (Wuhan, China) of 2010 Zhongnan Hospital of Wuhan University Animal Care and Use 025. Female, virgin BALB/c mice (7-9 weeks) were purchased from Hubei Medical Laboratory Animal Center (Wuhan, China) and were housed under a $12 / 12 \mathrm{~h}$ light/dark cycle at $25 \pm 0.5^{\circ} \mathrm{C}$ and $50-60 \%$ humidity. Mice were fed with 
a standard pellet diet and water. Smear samples of vaginal discharge were observed daily in order to identify the estrus. Only mice with more than two consecutive periods of regular 4-day estrus cycles were used in the present study. Suitable mice [age, 8-12 weeks; body weight (bw), 20-23 g] were randomly divided into three groups: The GnRH agonist treatment group $(n=10)$, the $\mathrm{GnRH}$ antagonist treatment group $(n=10)$ and the control (natural cycle) group $(n=10)$.

Ovarian stimulation. Treatment procedures were performed as previously described, but with minor revisions (19). In brief, mice in the GnRH agonist group received intraperitoneal (IP) injection with the GnRH agonist Decapeptyl ${ }^{\circledR}$ (Ferring Co., Kiel, Germany)) at $1.5 \mu \mathrm{g} / 100 \mathrm{~g}$ bw/day between days three and 9 of estrus. At 9 am of day 9, 20 IU/mouse human menopausal gonadotropin (HMG; Livzon Pharmaceutical Group Inc., Shanghai, China) was injected IP, followed by IP injection with $100 \mathrm{IU} / 100 \mathrm{~g}$ bw human chorionic gonadotrophin (HCG; Pregnyl ${ }^{\circledR}$; Organon International, Oss, Netherlands) at $28 \mathrm{~h}$ after the injection of HMG. Mice in the GnRH antagonist group received IP injection of the GnRH antagonist Cetrotide ${ }^{\circledR}$ (Serono Inc., Rockland, MA, USA) at $4 \mu \mathrm{g} / 100 \mathrm{~g}$ bw on day three of estrus. HMG was then injected at $20 \mathrm{IU} / \mathrm{mouse}$ IP at 9 am of day 9, followed by IP injection with $100 \mathrm{IU} / 100 \mathrm{~g}$ bw HCG $28 \mathrm{~h}$ after the injection of HMG. The mice in the control (natural cycle) group received IP injection with saline only at the same volume as the injections received by the mice in the GnRH agonist and antagonist groups, from day three of estrus onwards. The same injection schedule was followed as described for the GnRH agonist and antagonist groups.

Tissue collection and application. Fresh whole uterus samples were collected from the mice in the three groups $48 \mathrm{~h}$ after the treatment. Fresh whole uterus samples were quickly divided into four equal sections subsequent to being washed in cold phosphate-buffered saline. One uterus section was fixed in $2.5 \%$ glutaraldehyde at room temperature for $30 \mathrm{~min}$ and at incubated at $4^{\circ} \mathrm{C}$ overnight, prior to being fixed for $\geq 1 \mathrm{~h}$ in $1 \%$ osmium tetroxide in the dark for scanning electron microscopy (SEM) analysis. The remaining three sections of each sample were stored at $-80^{\circ} \mathrm{C}$ until required for protein, DNA and mRNA extraction.

Genomic DNA extraction and bisulfite sequencing polymerase chain reaction (BSP). Genomic DNA was extracted from the frozen tissue samples from the three groups using the DNeasy ${ }^{\circledR}$ Blood and Tissue kit (Qiagen, Valencia, CA, USA). The genomic DNA (500 ng) was then bisulfite-modified using the EZ DNA Methylation-Gold ${ }^{\mathrm{TM}}$ kit (Qiagen) according to the manufacturer's instructions. Bisulfite-modified DNA was dissolved in $20 \mu \mathrm{l}$ water and stored at $-80^{\circ} \mathrm{C}$.

Quantification of Hoxal0 promoter methylation in mice using BSP. A total of $200 \mathrm{ng}$ bisulfite-treated DNA was used in a $50 \mu \mathrm{l}$ reaction system containing $1.5 \mu \mathrm{l}$ forward and reverse primers (Table I), $1.25 \mathrm{mmol} / 1$ deoxynucleotide triphosphates, $25 \mathrm{mM} \mathrm{Mg}^{2+}$ and $0.5 \mu \mathrm{l}$ HotStarTaq DNA polymerase (Qiagen). The amplification conditions were as follows: $10 \mathrm{~min}$ at $95^{\circ} \mathrm{C}$ followed by 40 cycles of $95^{\circ} \mathrm{C}$ for $30 \mathrm{sec}, 53^{\circ} \mathrm{C}$ for $30 \mathrm{sec}$ and $72^{\circ} \mathrm{C}$ for $40 \mathrm{sec}$, then a final extension at $72^{\circ} \mathrm{C}$ for $10 \mathrm{~min}$. Polymerase chain reaction (PCR) products were resolved using electrophoresis on a $2 \%$ agarose gel and stained with GoldView (SBS Genetech Co., Ltd., Beijing, China). The appropriate-sized product bands were then isolated and excised from the gel and purified using a Gel Extraction kit (Axygen Biotechnology, Hangzhou, China) according to the manufacturer's instructions. The resultant products were sequenced using MicoRead Biotechnology (Beijing Microread Genetics Co., Ltd., Beijing, China).

Quantitative polymerase chain reaction ( $q P C R)$ analysis. Total RNA was extracted from the tissue samples using the REzol RNA extraction kit (SBS Genetech Co.,Ltd.) according to the manufacturer's instructions. Total RNA (100 ng) from each sample was treated with DNase and converted to complementary (c)DNA using the PrimeScript ${ }^{\mathrm{TM}}$ RT reagent kit (Takara Bio Inc., Dalian, China). mRNA levels were analyzed using an iQ5 Real-Time PCR detection system (Bio-Rad Laboratories, Inc., Hercules, CA, USA) with SYBR $^{\circledR}$ Premix Ex Taq ${ }^{\mathrm{TM}}$ II (Takara Bio Inc.). The primer sequences for Hoxa10, integrin $\beta 3$ and $\beta$-actin are listed in Table I. All primers were obtained from Servicebio (Wuhan, China).

The qPCR amplification conditions for Hoxa10 were as follows: 40 cycles of $95^{\circ} \mathrm{C}$ for $10 \mathrm{sec}, 62^{\circ} \mathrm{C}$ for $15 \mathrm{sec}$ and $72^{\circ} \mathrm{C}$ for $15 \mathrm{sec}$. The qPCR amplification conditions for integrin $\beta 3$ and $\beta$-actin were as follows: 40 cycles of $95^{\circ} \mathrm{C}$ for $10 \mathrm{sec}, 60^{\circ} \mathrm{C}$ for $15 \mathrm{sec}$ and $72^{\circ} \mathrm{C}$ for $15 \mathrm{sec}$. The increasing fluorescence of the PCR products during amplification was monitored to create a quantitative standard curve. Quantification of the target gene expression in the samples was assessed and adjusted to the quantitative expression of $\beta$-actin in the same samples. Melting curve analysis was conducted to determine the specificity of the amplified products and to ensure the absence of primer-dimer formation. All products obtained yielded the predicted melting temperature. Relative gene expression was calculated using the $2^{-\Delta \Delta \mathrm{Ct}}$ method.

Western blot analysis. Samples were lysed in radio-immunoprecipitation assay buffer (Beyotime, Shanghai, China) with protease inhibitors (Sigma-Aldrich, St. Louis, MO, USA) to extract whole-cell proteins. Protein levels were measured using the Micro Bicinchoninic Acid ${ }^{\mathrm{TM}}$ Protein Assay kit (Beyotime). Proteins were run on a precast $7.5 \%$ acrylamide gel (Beyotime) and transferred onto polyvinylidene fluoride membranes (Millipore Corporation, Billerica, MA, USA). Membranes were blocked with $5 \%$ fat-free milk in Tris-buffered saline with $0.1 \%$ Tween-20 followed by incubation with primary antibodies against Hoxa10 (AV100932; Sigma-Aldrich) and integrin $\beta 3$ (ab33171; Abcam PLC, Cambridge, UK). Membranes were then incubated with secondary antibodies rabbit anti-goat polyclonal antibody (ZDR-5308; Beijing Zhongshan Golden Bridge Biotechnology Co., Ltd., Beijing, China) or goat anti-rabbit polyclonal antibody (ZDR-5306; Beijing Zhongshan Golden Bridge Biotechnology Co., Ltd.) in blocking buffer, respectively. Immunoreactive bands were detected using a chemiluminescent detection kit (Beyotime). Densitometry measurements were analyzed using Quantity One v4.4.0 (Bio-Rad Laboratories, Inc.). Target protein expression levels were normalized to that of $\beta$-actin. 
Table I. Primer sequences used for BSP and qPCR.

\begin{tabular}{lll} 
Gene & \multicolumn{1}{c}{ Sense primer $\left(5^{\prime}-3^{\prime}\right)$} & \multicolumn{1}{c}{ Antisense primer $\left(5^{\prime}-3^{\prime}\right)$} \\
\hline Hoxa10 (BSP) & TATTTTGAGGTAGTTTTTATAGTTT & CAAATAACCCTTTCTAACTAACATTTC \\
Hoxa10 (qPCR) & CCTTCCGAGAGCAGCAAA & GTCTGGTGCTTCGTGTAGGG \\
Integrin $\beta 3(\mathrm{qPCR})$ & GCCTTCGTGGACAAGCCTGTA & GGACAATGCCTGCCAGTCTTC \\
$\beta$-actin $(\mathrm{qPCR})$ & TTCCAGCCTTCCTTCCTGG & TTGCGCTCAGGAGGAGCAAT
\end{tabular}

Hox, homeobox; qPCR, quantitative polymerase chain reaction; BSP, Bisulfite sequencing PCR.

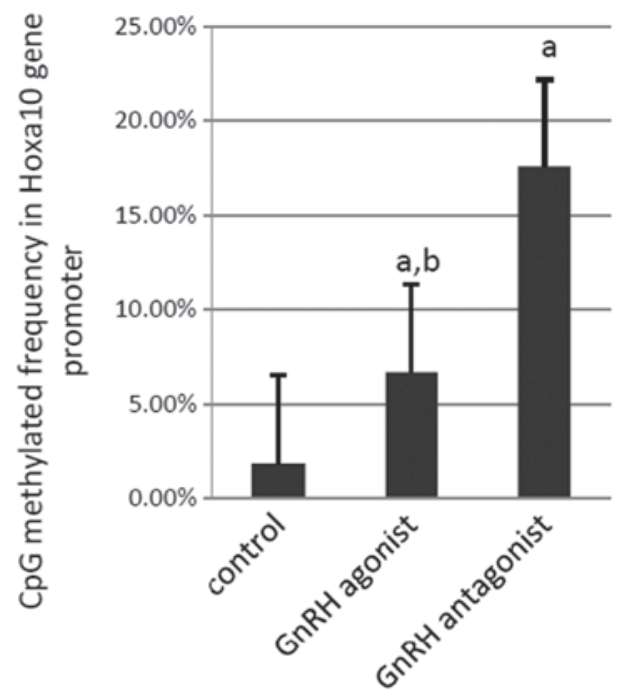

Figure 1. Methylation levels of the Hoxa10 gene promoter region in the uterus during the implantation window of $\mathrm{GnRH}$ analogue-exposed mice. ${ }^{\mathrm{a}} \mathrm{P}<0.01$ vs. the control (natural cycle) group; ${ }^{b} \mathrm{P}<0.01$ vs. the $\mathrm{GnRH}$ antagonist group. Hox, homeobox; GnRH, gonadotropin-releasing hormone.

SEM analysis. SEM was performed for morphological analysis and to confirm the presence of pinopodes in the endometrium of mice during the implantation window in the natural cycle or following GnRH agonist or antagonist treatment. For SEM preparation, endometrial tissues were fixed in $2.5 \%$ glutaraldehyde at room temperature for $30 \mathrm{~min}$ then at $4^{\circ} \mathrm{C}$ overnight, prior to being fixed for at least $1 \mathrm{~h}$ in $1 \%$ osmium tetroxide in the dark. Samples were then dehydrated in a graded series of ethanol, critical-point-dried, mounted and coated with gold in a sputter coater (JFC-1300 Auto Fine Coater; Jeol Ltd., Tokyo, Japan). Samples were observed using a scanning electron microscope (JSM-5600LV SEM, Jeol Ltd.). SEM was performed in order to observe the morphology of the pinopodes in the samples from the different groups.

Statistical analysis. Statistical analyses for western blot analysis, BSP and qPCR values were performed using SPSS 17.0 software (SPSS, Inc., Chicago, IL, USA). $\chi^{2}$ and analysis of variance tests were performed to compare the groups. $\mathrm{P}<0.05$ was considered to indicate a statistically significant difference.

\section{Results}

Hoxal0 promoter methylation status and GnRH-as. BSP was performed to examine the methylation status of the $21 \mathrm{CpG}$ sites in the Hoxa10 promoter in each sample. In total, $210 \mathrm{CpG}$ sites were analyzed in each experimental group. A total of $37(17.6 \%)$ methylated $\mathrm{CpG}$ sites were observed in the samples from the GnRH antagonist group, compared with 14 (6.7\%) methylated sites in the samples from the GnRH agonist group and four $(1.9 \%)$ methylated sites in the samples from the control group (GnRH antagonist vs. control, $\mathrm{P}<0.001$; GnRH agonist vs. control, $\mathrm{P}=0.006$ and $\mathrm{GnRH}$ agonist vs. $\mathrm{GnRH}$ antagonist, $\mathrm{P}=0.008$; Fig. 1 ). Thus, compared with the mice in the control group, the levels of methylation within the Hoxa10 promoter sequence were found to be higher in the mice that had received GnRH-as treatment, particularly in those treated with the GnRH antagonist.

Endometrial Hoxal0 and integrin $\beta 3$ mRNA expression during the implantation window following GnRH-as treatment. Hoxa10 and integrin $\beta 3$ mRNA were expressed during the implantation window in the uteri of the mice in all three groups. Following normalization to $\beta$-actin expression, Hoxa10 mRNA expression was observed to be significantly decreased in the mice in the GnRH antagonist and agonist groups compared with the control group $(\mathrm{P}<0.001$ and $\mathrm{P}=0.004$, respectively; Fig. 2A). Compared with the control group, integrin $\beta 3$ mRNA expression was also found to be reduced in the mice in the GnRH antagonist and agonist groups $(\mathrm{P}<0.001$ and $\mathrm{P}=0.002$, respectively; Fig. 2B). Furthermore, Hoxa10 and integrin $\beta 3$ mRNA expression were observed to be higher in the GnRH agonist group compared with the GnRH antagonist group $(\mathrm{P}=0.044$ and $\mathrm{P}=0.032$, respectively; Fig. 2A and $\mathrm{B})$

Endometrial Hoxal0 and integrin $\beta 3$ protein expression during the implantation window following GnRH-as treatment. The protein expression of endometrial Hoxa10 and integrin $\beta 3$ were detected using western blot analysis during the implantation window in the uteri of the mice in the three groups (Fig. 3A). In accordance with the mRNA expression findings, following normalization to $\beta$-actin expression, Hoxa10 protein expression was found to be lowest in the mice in the GnRH antagonist treatment group and highest in the mice in the control group (GnRH agonist vs. control, $\mathrm{P}=0.032$; GnRH antagonist vs. control, $\mathrm{P}=0.047$ and $\mathrm{GnRH}$ agonist vs. $\mathrm{GnRH}$ antagonist, $\mathrm{P}=0.005)$. Integrin $\beta 3$ expression was also observed to be lowest in the mice in the GnRH antagonist group and highest in those in the control group ( GnRH agonist vs. control, $\mathrm{P}=0.006$; $\mathrm{GnRH}$ antagonist vs. control $\mathrm{P}=0.004$ and $\mathrm{GnRH}$ agonist vs. GnRH antagonist, $\mathrm{P}=0.0041$; Fig. 3C). 


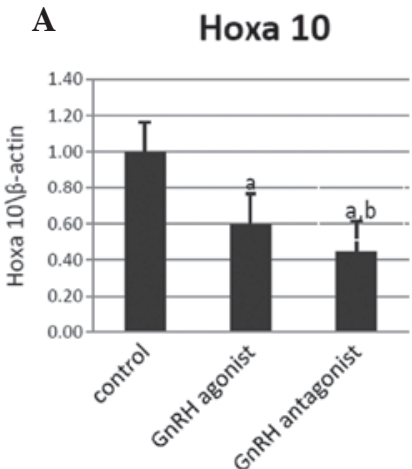

B Integrin $\beta 3$

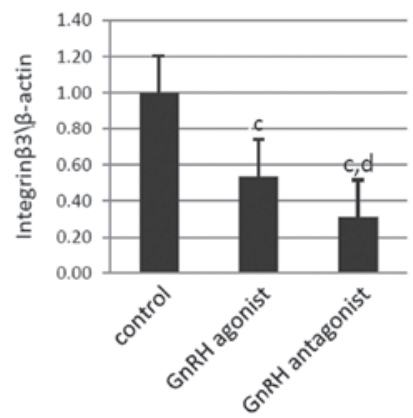

Figure 2. Levels of (A) Hoxa10 and (B) integrin $\beta 3$ mRNA during the implantation window in the uteri of mice in the GnRH agonist, GnRH antagonist and control groups, measured using quantitative polymerase chain reaction analysis. Data are presented as the mean \pm standard error of the mean of the protein expression of the target gene relative to that of $\beta$-actin. The mRNA levels of Hoxa10 and integrin $\beta 3$ in the mice in the GnRH analogue groups, particularly the GnRH antagonist group, were lower than those in the control mice. ${ }^{\mathrm{a}, \mathrm{c}} \mathrm{P}<0.01$ vs. control; ${ }^{\mathrm{b}, \mathrm{d}} \mathrm{P}<0.05$ vs. GnRH agonist. Hox, homeobox; GnRH, gonadotropin-releasing hormone.
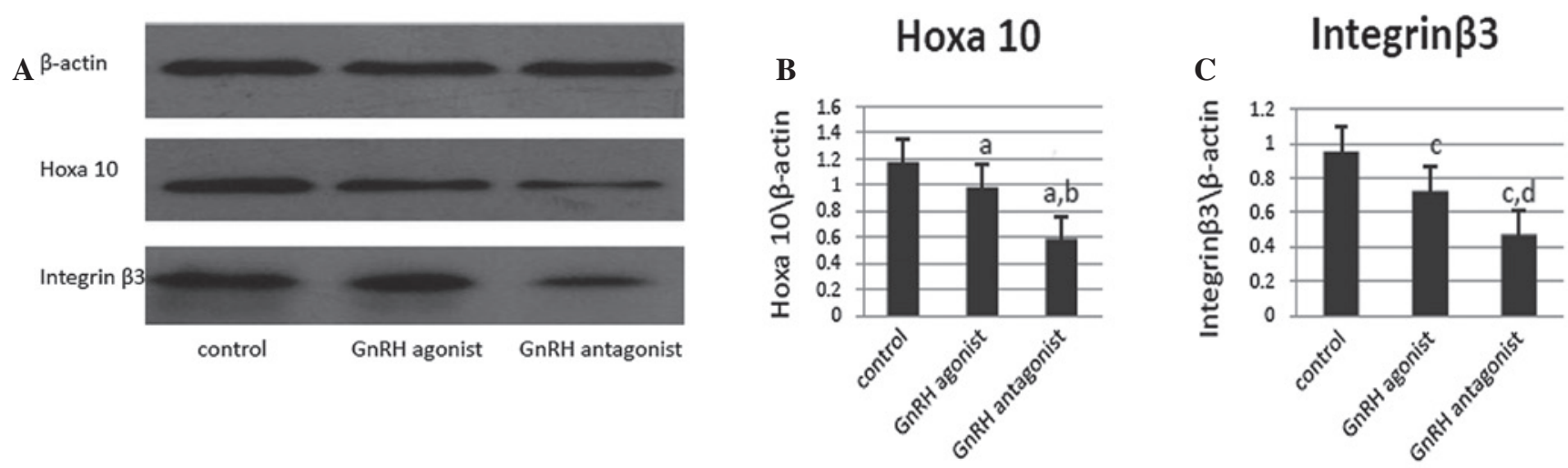

Figure 3. (A) Hoxa10 and integrin $\beta 3$ protein expression during the implantation window in the uteri of GnRH analogue-exposed mice, measured using western blot analysis. $\beta$-actin protein expression was used as an internal loading control. (B) Hoxa10 protein expression in the mice in the GnRH agonist, GnRH antagonist and control groups. (C) Integrin $\beta 3$ protein expression in the mice in the GnRH agonist, GnRH antagonist and control (natural cycle) groups. Data are presented as the mean \pm standard error of the mean of the protein expression of the target gene relative to that of $\beta$-actin. ${ }^{a} \mathrm{P}<0.05$ vs. the control group; ${ }^{b} \mathrm{P}<0.01$ vs. the $\mathrm{GnRH}$ agonist group; ${ }^{\mathrm{P}} \mathrm{P}<0.01$ vs. the control group; and ${ }^{\mathrm{d}} \mathrm{P}<0.05$ vs. the $\mathrm{GnRH}$ agonist group. Hox, homeobox; GnRH, gonadotropin-releasing hormone.
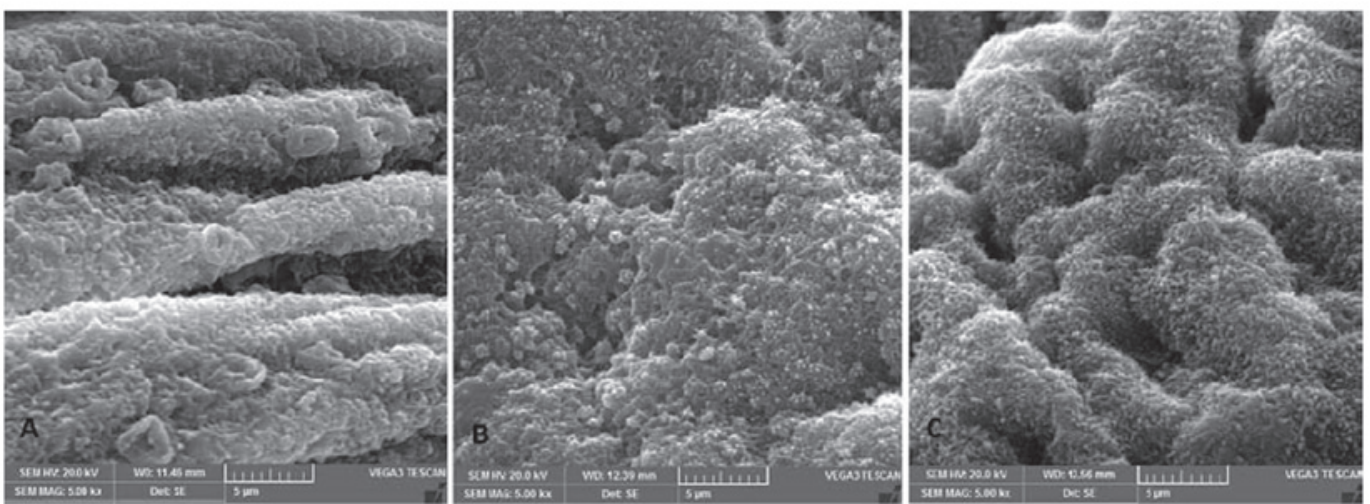

Figure 4. Scanning electron microscopy showing pinopodes of the luminal uterine epithelium during the implantation window in GnRH analogue-exposed mice. Mice in the GnRH agonist and GnRH antagonist groups exhibited reduced pinopode formation. (A) The luminal uterine epithelium of the mice in the control (natural cycle) group exhibited several fully developed pinopodes and a smooth surface; (B) the luminal uterine epithelium of the mice in the GnRH agonist group exhibited several developing pinopodes with a villous surface. (C) The luminal uterine epithelium of the mice in the GnRH antagonist group exhibited regressing pinopodes and a ciliated, microvillous surface with few/no pinopodes. Magnification, x5,000. GnRH, gonadotropin-releasing hormone.

Pinopode development following GnRH-as treatment. SEM photomicrographs of the endometrial luminal surface of the uterus during the implantation window were captured to identify the developmental status of the pinopodes (Fig. 4). Pinopode development was observed to be repressed in the GnRH agonist and GnRH antagonist groups compared with 
the control group. The mice in the control group exhibited fully developed pinopodes on the apical pole of the majority of the non-ciliated epithelial cells (Fig. 4A). However, in the mice in the GnRH agonist group, the pinopodes were less developed and the luminal uterine epithelium exhibited a villous surface (Fig. 4B). Pinopode development in the mice in the $\mathrm{GnRH}$ antagonist group was repressed and delayed, with the luminal uterine epithelium being ciliated and microvillous and exhibiting few pinopodes (Fig. 4C).

\section{Discussion}

The lower pregnancy rates in $\mathrm{COH}$ cycles during ART treatment may be a consequence of the negative effects of GnRH-as on endometrial receptivity; however, the specific mechanism has yet to be elucidated (1-2,20). The present study investigated Hoxa10 DNA methylation patterns and expression, as well as the effect of GnRH agonist and antagonist treatment on endometrial receptivity during the implantation window in mice.

In the present study, methylation in the promoter region of Hoxa10 was found to increase following GnRH agonist and antagonist treatment, with such increases being most evident under GnRH antagonist treatment. Hoax10 is a well established biomarker for endometrial receptivity and alterations in its methylation have been demonstrated to be associated with disturbances in endometrial receptivity in several pathological endometrial conditions, including reproductive system diseases and exposure to environmental endocrine disruptors (12-17). Several studies have shown that methylation regulation may be involved in endometrial development during the adult menstrual cycle and endometrial decidualization (21-23). In addition, increasing evidence has suggested that epigenetic mechanisms may regulate numerous aspects of pregnancy and the outcome of ART, with roles in implantation, placentation and foetal growth (24-26). Therefore, Hoxa10 methylation may be involved in endometrial receptivity following $\mathrm{GnRH}$-as treatment. To the best of our knowledge, this is the first study to show the methylation pattern of Hoxa10 following GnRH agonist and antagonist treatment.

In the present study, compared with the natural cycle control mice, Hoxa10 mRNA and protein expression was observed to decrease following GnRH-as treatment, particularly following GnRH antagonist treatment. This finding is supported by several studies, which have reported that despite there being no evidence to suggest that GnRH-as negatively effects oocyte quality, fertilization rates or embryo quality, $\mathrm{GnRH}$-as treatment is associated with a statistically significant reduction in pregnancy rates (1-2). Thus, this reduction in pregnancy rates associated with GnRH-as treatment may be due to the negative effects associated with GnRH-as, particularly GnRH antagonists, on the endometrium and the repression of endometrial receptivity (27-29). Altered HOXA10 expression may be caused by aberrant methylation of the gene, with promoter hypermethylation often correlated with suppressed gene expression $(9,30)$. Therefore, the aberrant expression of Hoxa10 in the mouse endometrium following GnRH-as treatment may result from altered Hoxa10 DNA methylation.
Like Hoxa10 expression, following GnRH-as treatment the expression of integrin $\beta 3$ and pinopode development were also reduced in the present study. Furthermore, Quinn and Casper (31) also reported that downregulation of Hoxa10 caused a reduced number of pinopodes, while overexpression of Hoxa10 resulted in an increase in pinopode numbers (31). Endometrial integrin $\beta 3$ and pinopodes are characteristic biomarkers closely associated with endometrial development and maturation and they peak in expression during the implantation window (31-33). Therefore, the repressed endometrial receptivity observed following GnRH-as treatment may be due to altered Hoxa10 expression. The findings of the present study are supported by previous studies reporting decreased integrin $\beta 3$ subunit expression following GnRH-as intervention $(1,19,32)$.

Further investigations are required to identify the mechanism by which GnRH agonists and antagonists cause Hoxa10 gene promoter hypermethylation. The methylation pattern in humans may be different to that in mice; therefore, investigations on endometrial biopsies from patients undergoing $\mathrm{COH}$ should be performed in the future.

In conclusion, the present study has shown that GnRH-as may influence the methylation status of the Hoxa10 gene in mice, which may affect uterine receptivity and repress the expression of endometrial integrin $\beta 3$ and pinopode development. These findings present a potential epigenetic mechanism by which GnRH-as, particularly GnRH antagonists, may negatively affect endometrial receptivity. These findings may explain the low implantation rate associated with $\mathrm{COH}$ treatments, which involve GnRH-as in human in vitro fertilization clinics. However, additional studies are required to analyze the impact of methylation regulation, particularly epigenetic regulation by GnRH-as, on the endometrium.

\section{Acknowledgements}

The present study was supported by grants from the National Key Basic Research Program of China (grant no. 2012CB526600), the Key Research Program from the Health Department of Hubei Province (grant no. JX5A05), National Natural Science Foundation of China (grant no. 81100411) and the Fundamental Research Funds for the Central Universities of China (grant no. 2012303020204).

\section{References}

1. Rackow BW, Kliman HJ and Taylor HS: GnRH antagonists may affect endometrial receptivity. Fertil Steril 89: 1234-1239, 2008.

2. Al-Inany HG, Abou-Setta AM and Aboulghar M: Gonadotrophin-releasing hormone antagonists for assisted conception: a Cochrane review. Reprod Biomed Online 14: 640-649, 2007.

3. Bourgain C and Devroey P: The endometrium in stimulated cycles for IVF. Hum Reprod Update 9: 515-522, 2003.

4. Devroey P, Bourgain C, Macklon NS and Fauser BC: Reproductive biology and IVF: ovarian stimulation and endometrial receptivity. Trends Endocrinol Metab 15: 84-90, 2004.

5. Kolibianakis E, Bourgain C, Albano C, et al: Effect of ovarian stimulation with recombinant follicle-stimulating hormone, gonadotropin releasing hormone antagonists, and human chorionic gonadotropin on endometrial maturation on the day of oocyte pick-up. Fertil Steril 78: 1025-1029, 2002.

6. Taylor HS: The role of HOX genes in human implantation. Hum Reprod Update 6: 75-79, 2000. 
7. Taylor HS, Vanden Heuvel GB and Igarashi P: A conserved HOX axis in the mouse and human female reproductive system: late establishment and persistent adult expression of the HOXA cluster genes. Biol Reprod 57: 1338-1345, 1997.

8. Satokata I, Benson G and Maas R: Sexually dimorphic sterility phenotypes in HOXA10-deficient mice. Nature 374: 460-463, 1995.

9. Wu Y, Halverson G, Basir Z, et al: Aberrant methylation at HOXA10 may be responsible for its aberrant expression in the endometrium of patients with endometriosis. Am J Obstet Gynecol 193: 371-380, 2005.

10. Daftary GS, Troy PJ, Bagot CN, et al: Direct regulation of beta3-integrin subunit gene expression by HOXA10 in endometrial cells. Mol Endocrinol 16: 571-579, 2002.

11. Taylor HS, Daftary GS and Selam B: Endometrial HOXA10 expression after controlled ovarian hyperstimulation with recombinant follicle-stimulating hormone. Fertil Steril 80 (Suppl 2): 839-843, 2003.

12. Kim JJ, Taylor HS, Lu Z, et al: Altered expression of HOXA10 in endometriosis: potential role in decidualization. Mol Hum Reprod 13: 323-332, 2007

13. Nasu K, Kawano Y, Tsukamoto Y, et al: Aberrant DNA methylation status of endometriosis: epigenetics as the pathogenesis, biomarker and therapeutic target. J Obstet Gynaecol Res 37: 683-695, 2011.

14. Rackow BW, Jorgensen E and Taylor HS: Endometrial polyps affect uterine receptivity. Fertil Steril 95: 2690-2692, 2011.

15. Widschwendter M, Apostolidou S, Jones AA, et al: HOXA methylation in normal endometrium from premenopausal women is associated with the presence of ovarian cancer: a proof of principle study. Int J Cancer 125: 2214-2218, 2009.

16. Bromer JG, Wu J, Zhou Y and Taylor HS: Hypermethylation of homeobox A10 by in utero diethylstilbestrol exposure: an epigenetic mechanism for altered developmental programming. Endocrinology 150: 3376-3382, 2009.

17. Varayoud J, Ramos JG, Bosquiazzo VL, Muñoz-de-Toro M, and Luque EH: Developmental exposure to Bisphenol a impairs the uterine response to ovarian steroids in the adult. Endocrinology 149: 5848-5860, 2008

18. Hiyama M, Choi EK, Wakitani S, et al: Bisphenol-A (BPA) affects reproductive formation across generations in mice. J Vet Med Sci 73: 1211-1215, 2011.

19. Ruan HC, Zhu XM, Luo Q, et al: Ovarian stimulation with GnRH agonist, but not $\mathrm{GnRH}$ antagonist, partially restores the expression of endometrial integrin beta3 and leukaemia-inhibitory factor and improves uterine receptivity in mice. Hum Reprod 21: 2521-2529, 2006.
20. Shapiro BS, Daneshmand ST, Garner FC, et al: Evidence of impaired endometrial receptivity after ovarian stimulation for in vitro fertilization: a prospective randomized trial comparing fresh and frozen-thawed embryo transfer. Fertil Steril 96 344-348, 2011

21. Yamagata Y, Asada H, Tamura I, et al: DNA methyltransferase expression in the human endometrium: down-regulation by progesterone and estrogen. Hum Reprod 24: 1126-1132, 2009.

22. Munro SK, Farquhar CM, Mitchell MD and Ponnampalam AP: Epigenetic regulation of endometrium during the menstrual cycle. Mol Hum Reprod 16: 297-310, 2010.

23. Vincent ZL, Farquhar CM, Mitchell MD and Ponnampalam AP Expression and regulation of DNA methyltransferases in human endometrium. Fertil Steril 95: 1522-1525, 2011.

24. Logan PC, Ponnampalam AP, Rahnama F, et al: The effect of DNA methylation inhibitor 5-Aza-2'-deoxycytidine on human endometrial stromal cells. Hum Reprod 25: 2859-2869, 2010.

25. van Montfoort AP, Hanssen LL, de Sutter P, et al: Assisted reproduction treatment and epigenetic inheritance. Hum Reprod Update 18: 171-197, 2012

26. Horsthemke B and Ludwig M: Assisted reproduction: the epigenetic perspective., Hum Reprod Update 11: 473-482, 2005.

27. Tarlatzis BC and Bili HN: Gonadotropin-releasing hormone antagonists: im-pact of IVF practice and potential nonassisted reproductive technologyapplications. Curr Opin Obstet Gynecol 15: 259-264, 2003.

28. Ludwig M, Katalinic A and Diedrich K: Use of GnRH antagonists in ovarian stimulation for assisted reproductive technologies compared to the long protocol. Meta-analysis. Arch Gynecol Obstet 265: 175-182, 2001.

29. Olivennes F, Cunha-Filho JS, Fanchin R, et al: The use of GnRH antagonists in ovarian stimulation. Hum Reprod Update 8: 279-290, 2002.

30. Grimaldi G, Christian M, Quenby S and Brosens JJ: Expression of epigenetic effectors in decidualizing human endometrial stromal cells. Mol Hum Reprod 18: 451-458, 2012.

31. Quinn CE and Casper RF: Pinopodes: a questionable role in endometrial receptivity. Hum Reprod Update 15: 229-236, 2009.

32. Creus M, Ordi J, Fábregues F, et al: $\alpha v \beta 3$ integrin expression and pinopod formation in normal and out-of-phase endometria of fertile and infertile women. Hum Reprod 17: 2279-2286, 2002.

33. Creus M, Ordi J, Fábregues F, et al: The effect of different hormone therapies on integrin expression and pinopode formation in the human endometrium: a controlled study. Hum Reprod 18: 683-693, 2003. 